\title{
Covid 19: The Impetus to Migrate Face-To-Face ACLS to Hybrid-ACLS
}

\author{
Fatimah Lateef ${ }^{1 *}$, Madhavi Suppiah ${ }^{2}$, Tan Suan Kai ${ }^{3}$ \\ ${ }^{1 *}$ Senior Consultant, Director, SingHealth Duke NUS Institute of Medical Simulation (SIMS), Singapore. \\ ${ }^{2}$ Assistant Director, Singhealth Duke-NUS Institute of Medical Simulation (SIMS), Singapore. \\ ${ }^{3}$ Executive, Singhealth Academy (Learning Development), Singapore. \\ *Corresponding Author: Prof F Lateef, Dept of Emergency Medicine, Singapore General Hospital, Singapore.
}

\section{Abstract}

When COVID 19 struck, many of our educational programs and courses had to be modified and adjusted to ensure the criteria of restriction face to face contact as well as group gathering size is met. One of the courses affected was the Advanced Cardiac Life Support (ACLS) Course. We decided to transform our fully face to face ACLS course to a hybrid ACLS course with an added e-learning component. We started to do this step by step, from scratch. The new hybrid ACLS course has multiple benefits in our system, provided it is properly planned, conceptualized and executed. The promotion of self-learning and empowerment, time-savings in the face to face components which is important for the busy healthcare providers, the flexibility and mobility of the learning are all positive outcomes. Some learners also feel greater psychological safety with the e-learning components as they can spend a longer time or as much time as they need to understand and assimilate the facts. Besides this, the hybrid model also allows for the practice of the hands-on skills, inter-professional collaborative practice and inculcation of the appropriate attitude and behavior. The authors share their thought process and execution of their Hybrid-ACLS Course.

Keywords: ACLS, hybrid learning, simulation-based learning, e-learning, computer-based simulation

\section{INTRODUCTION}

When COVID 19 struck, the educational landscape had to transform quickly in order to ensure the least amount of disruption to learning and at the same time adhering to restrictions such as safe distancing, wearing of masks and enhanced personal hygiene measures. $(1,2)$ The role of simulation centers and simulation-based education had to evolve.(3) One of the commonest and most frequently run course is Advanced Cardiac Life Support (ACLS). ACLS training provides instructions on the management of acute life threatening medical emergencies such as cardiac arrest and serious arrhythmias. It also includes airway management, drug therapy and post resuscitative care.(4-6) It represents a foundational course which all practicing physicians as well as certain groups of nurses (eg. specialist nurses working in Intensive Care Units, nurses in the Emergency Departments) need to be certified in. At the SingHealth Duke NUS Institute of Medical Simulation (SIMS), which is part of the SingHealth Duke NUS Academic Medical Center (AMC), both the provider as well as recertification ACLS course is conducted for some 1500 participants annually.

The usual face-to-face ACLS provider course at SIMS comprises of the following:

a. Half day face-to-face interactive lectures, covering all the relevant topics in ACLS

b. Half day of practical/ hands-on practice with instructors and review of scenarios

c. Testing (both theory and practical)

For the ACLS recertification course, it is made up of:

a. A one hour face-to-face interactive lecture to review the theory topics and the relevant updates to the guidelines

b. A 2 hour practical/ hands-on practice session with instructors, followed by 
c. The theory and practical testing

The provider course is for 1.5 days whilst the recertification course takes about 5 hours. Prior to coming for the face-to-face course and training, participants would have been sent the ACLS book and reading materials some $2-3$ weeks earlier, for their reading and understanding.

With COVID 19, the number of ACLS training sessions were significantly reduced and the size of each small group cannot exceed 5 persons (ie. 4 learners to one instructor). As a result of this, the plans for implementation of our hybrid- ACLS model was brought forward. This would be able to shorten the training time, especially the face-to-face component. At the same time, as part of transformative learning, it would also inculcate greater self- responsibility and ownership for the adult learners coming for the ACLS course. $(2,7)$

\section{PlanNing The Hybrid-Acls}

In planning the Hybrid-ACLS course and training materials, the first steps included: (4,6-9)

1. Identifying the objectives. This must align with the goals of ACLS which essentially is focused on emergency management of patients, airway management as well as rhythm recognition with appropriate interventions

2. Creating realistic and relevant scenarios to illustrate the objectives

3. Ensuring the narrative is clear, the characters come alive and can engage the learners in a stimulating and productive way, online.

4. Ensuring the adequate balance between the e-learning component, face-to-face interactive lectures as well as the actual hands-on skills training portions.

Essentially, the e-learning component of the ACLS must be able to mimic the environment or conditions similar to real-life situations for learners to explore, practice and prepare for the tasks they are supposed to carry out. It can offer an active learning experience and will be the precursor before the learners come for the shortened face-to-face hands-on session to practice the skills.(10-11) The scenarios that are designed should resonate with the realistic situation or environment of the learners. They should showcase and share workplace challenges. The "story" in the scenario should have a beginning, a body and a conclusion; with a compelling narrative. The 'interactive' portions of the scenarios would be considered necessary as it was felt that this would drive the engagement and empowerment of our learners, when they feel they are 'contributing' and 'doing something' for the 'patient'. It should be able to bring all the necessary elements and tie the learning components seamlessly. It was also a consideration whether to add videos with real actors with the hope to inspire and deepen understanding. $(9,11,12,13)$

The proposed new model for our Hybrid- ACLS training (both provider and recertification courses) with the e-ACLS modules would be as follows:

a. Pre-learning via the e-learning ACLS modules. The ACLS modules will be incorporated into the institution's Learning Management System together with the relevant reading materials. The glossary with the login details will be sent to all registered participants prior to coming for the course. This was to be completed in their own time

b. A half an hour face-to-face interactive lecture to review the theory topics and the relevant updates to the guidelines

The time allocated for the practical training and review of scenarios remain the same. The time spent for the ACLS provider course will be significantly reduced. For the recertification course, participants are able to access more information in an interactive manner instead of the 1 hour lecture held previously. With the COVID 19 pandemic, the conversion of many educational initiatives to virtual format and the need for distancing. This was indeed significant face-time savings.

\section{The Educational Principles Involved in THE HYBRID-ACLS}

In transforming our face-to-face ACLS to the new model, several educational principles and strategies were applied. There were adult learning principles which focused on the fact that adult learners are internally motivated, self-directed, goal oriented, practical, relevancy oriented, come with their own set of life experiences and knowledge as well as the need to be respected.(13) E-learning principles which involved the use of electronic media and technology for learning purposes was also applied. This utilized an online platform and can be part of a distance 
learning process. The term 'e-learning' can at times be used interchangeably with computer-based learning. $(2,9,10,11)$ There was also the flipped classroom model which is an instructional strategy whereby engagement and learning was enhanced by having the learners complete preparation work and readings before coming to a class. Class-time is then utilized for active discussion, group work and applications of the content and principles learnt. $(14,15)$

Simulation-based learning is another educational strategy that can help in the inculcation and development of health professionals' knowledge, skills, and attitudes, whilst protecting patients from being exposed to unnecessary risks. Simulationbased medical education can be a platform for various types of learning, including resolution of practical dilemmas. Simulation based training techniques, tools, and strategies can be applied in designing structured learning experiences, as well as be utilized as a measurement tool linked to targeted teamwork competencies and learning objectives. Simulationbased learning itself is not new. It has been applied widely in the aviation industry (also known as CRM or crew resource management), anesthesiology, as well as in the military. It helps to mitigate errors and maintain a culture of safety, especially in the industries where there is zero tolerance for any deviation from set standards. In Medicine, simulation can be used to help inculcate clinical reasoning amongst learners, which is a fundamental model for deepening understanding. (16-19)

\section{The E-LEARning Component of THE HYBRID-ACLS}

This represent the newly added component to our Hybrid- ACLS training. In planning this portion, the subject matter experts were paired with the IT or technical expert to review some of the principles of e-learning that were to be used. Decision on the principle of multi-media use and the balance between words, graphics, visual and auditory elements and use of animation or pop-up boxes as cues were decided upon. The contiguity principle was also important when considering whether to present words and images simultaneously or successively. This type of decision can be based on the concept of how information can be processed concurrently to facilitate retention. Also, if the words and graphics are kept on screen whilst the voice-over explains the concept or algorithm, it may facilitate information and content processing by learners. We tested this with learners of varying seniority during this brainstorming stage. $(9,10,11)$ Whatever the decision, the cognitive load must not be too high. As we know, ACLS is a relatively content-heavy course with a lot of information incorporated in the curricula. Irrelevant words, images and audio inputs should be removed in alignment with the coherence principle, where less can be more. (9.20.21)

For the voice-over component, a soothing and nurturing voice tone was adopted rather than an authoritative one, to keep learners at ease. A more 'human tone' is better than a robotic voice to make the learning more intimate and realistic. As ACLS has several modules, we also decided to segment them into bite-size micromodules, so as not to overload the learners and they can take breaks between each segment and come back later to complete these. $(4,6)$ This concept of microlearning can help understanding and retention as well. Learners can do the e-learning component in their own time, before coming for the face-to-face training, The instructions for the e-learning component will be shared when they log on and there is also a pre-test multiple choice questions (MCQs) section to assess their prior knowledge and understanding. Upon completion of the whole e-learning modules, there are post-test MCQs for them to try out as well.

Planning and starting up the e-learning component of our Hybrid-ACLS can cost more in the beginning but the delivery cost will be much lower, in the longer term.(22) The time savings are important as well, especially considering the challenges brought on by the COVID 19 pandemic. E-learning can reach out to a wider audience faster, is suited for adult self-directed learners where they can self-pace and customize according to their time and capabilities. The modular approach using micro-learning is also very wellreceived by learners who can break-up their learning into small segments.(9) Our e-learning platform at SIMS allows back room collection and tracking of data. It was planned thus to assist the organizers and faculty in reviewing the program and need for any changes if certain disturbing trends were noted. The system is very learner-centric as well. They can utilize it in a synchronous way (ie. in real time) or asynchronous fashion at anytime, at their convenience. The modules were planned to integrate cognitive skills, interpersonal and communication skills as well as the knowledge of psycho-motor skills required (the actual psycho-motor component will be better tested with the face-to-face training session). The e-learning portion allows for distance learning, from home or anywhere else. (10-13) 
Covid 19: The Impetus to Migrate Face-To-Face ACLS to Hybrid-ACLS

\section{E-Learning Insert}

For the e-learning modules, we decided on 8 different scenarios, with each case as its own unique topic which tests the participants on their prior knowledge of the topic as well as beefing up new information as required through various interactive activities integrated through the module.(Fig 1) This is usually done at the story board development stage where we have to plan screen by screen, what should happen in the scenarios. Avatars or figures representing a particular person or character have multiple uses in our e-learning modules. They can help guide learners

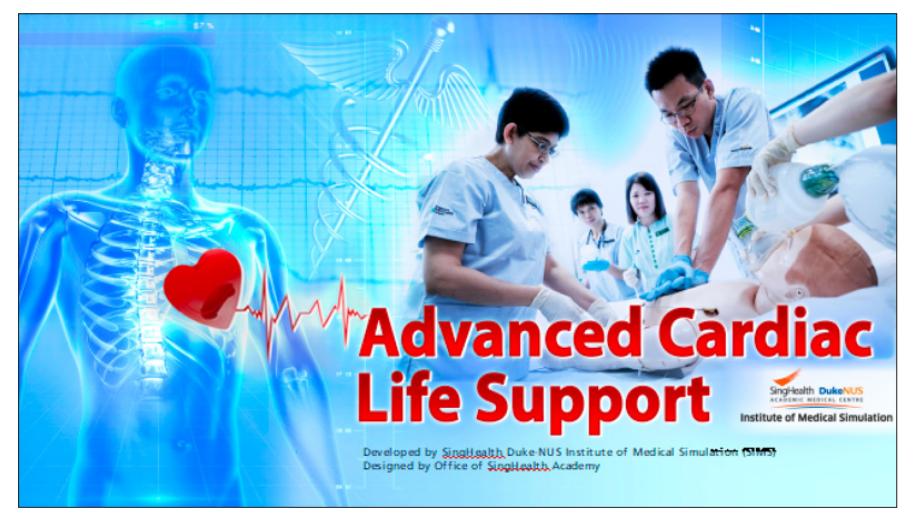

through each scenario, provide advice and tips at strategic points as well as decision making points in the scenarios or even help to inform learners of the narrative/ story involving the patient/ avatar. These avatars can make the scenarios come to life and be more realistic and engaging.

The ACLS algorithm will be available as a side tab in the event there is a need to refer to this at any point whilst negotiating each scenario. (Fig 2) The participants would also have to go through a formative assessment at the end of the course.

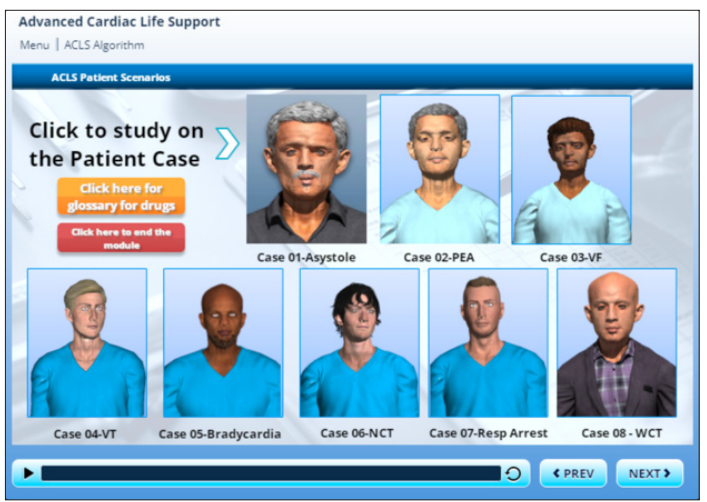

Fig1. The opening page of the e-learning ACLS modules with the introduction of the 8 characters/patients involved in negotiating the scenarios.

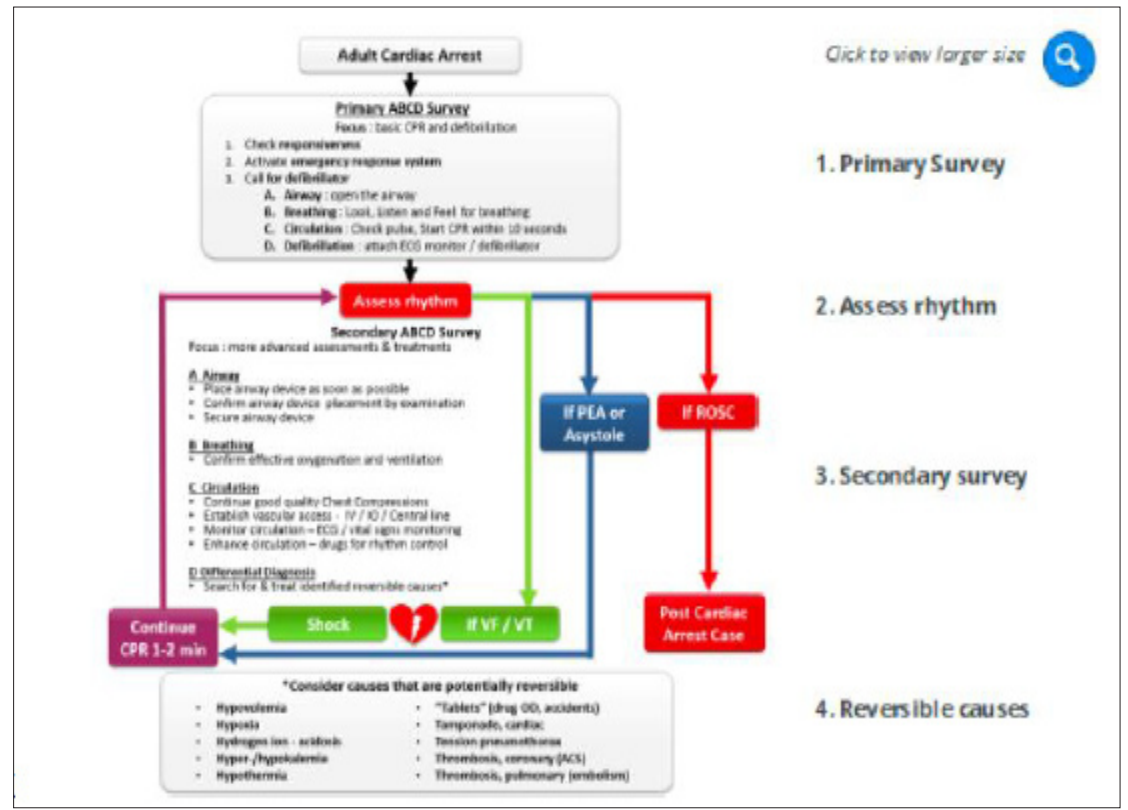

Fig2. The general ACLS Algorithm

In the design, there are quick links for participants to reference important information such as the ACLS algorithm and selected important drugs that are frequently used with relation to the topic in the 
Covid 19: The Impetus to Migrate Face-To-Face ACLS to Hybrid-ACLS

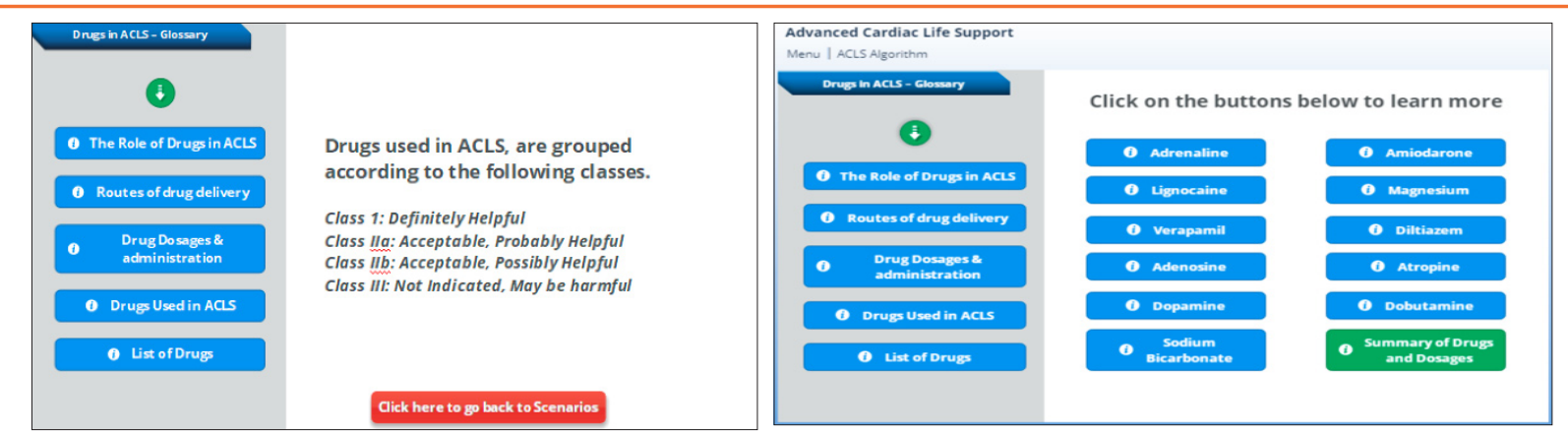

Fig3. List of drugs as "quick link tab"

The different topics are categorized and given a tab of its own so that it would be easier for a participant to navigate through the glossary to find these. For example, if looking for a specific drug in this list, they would not have to flip through the whole glossary to look for it. This method of information delivery is more precise and concise for the participants.

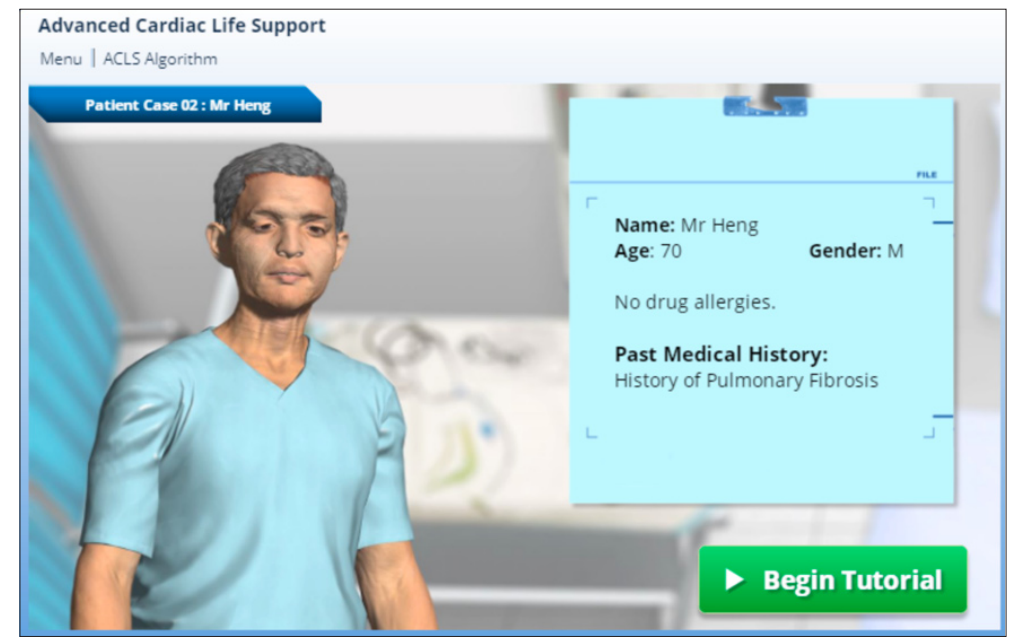

Fig4. The scenario page for each case study

Before the participants start each scenario, approaches maybe different depending on the they are given some background information underlying conditions and background history regarding the patient to prepare them for each that each patient may possess. This is done to unique case study. This is because treatment and enhance the realism of the case. (Fig 4)

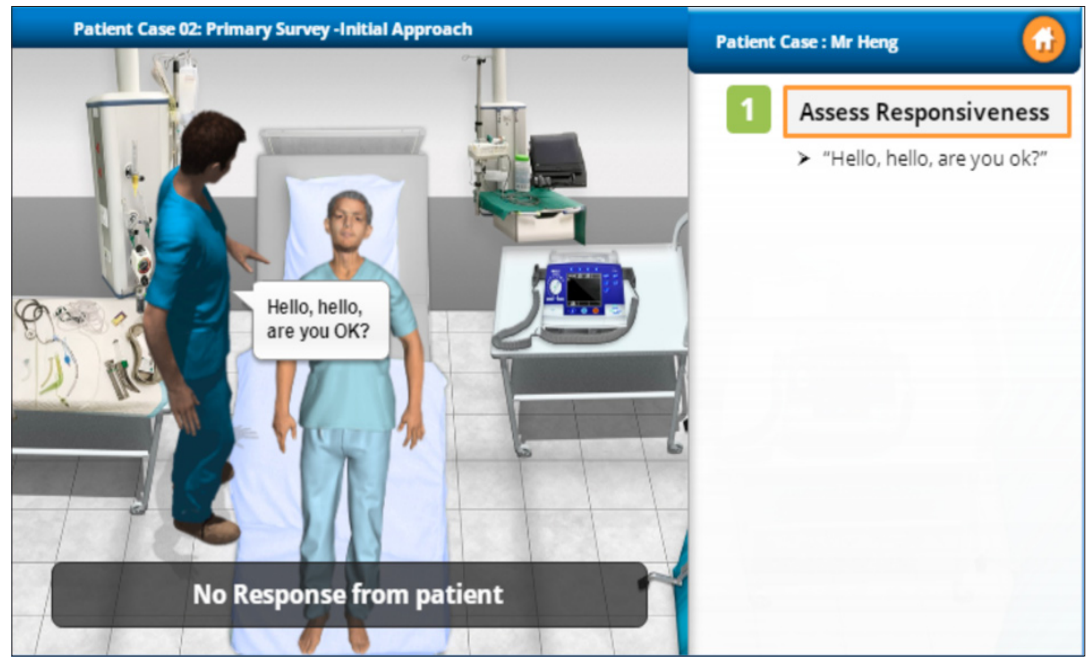

Fig5. Scenario based simulation of events 
Covid 19: The Impetus to Migrate Face-To-Face ACLS to Hybrid-ACLS

As the participants begin the case study, they will go through a simulation based scenario which is animated to mimic the interaction between the patient and themselves as the healthcare provider. In the side window on the right, each step will be listed

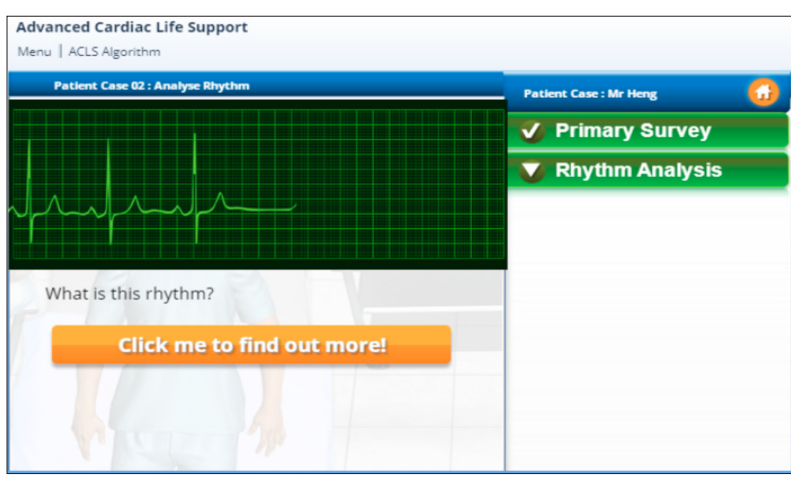

Fig6. Simulation of cardiac monitor for rhythm

The different rhythm animations are also added appropriately to each unique case to enhance realism. (Fig 6) There are also quizzes to check and test the participant's prior knowledge or new knowledge that has just been acquired out in accordance with the ACLS algorithm which the participant will click through at their own pace. This would cater to a larger group of different learners and better deliver the necessary information as required. (Fig 5)

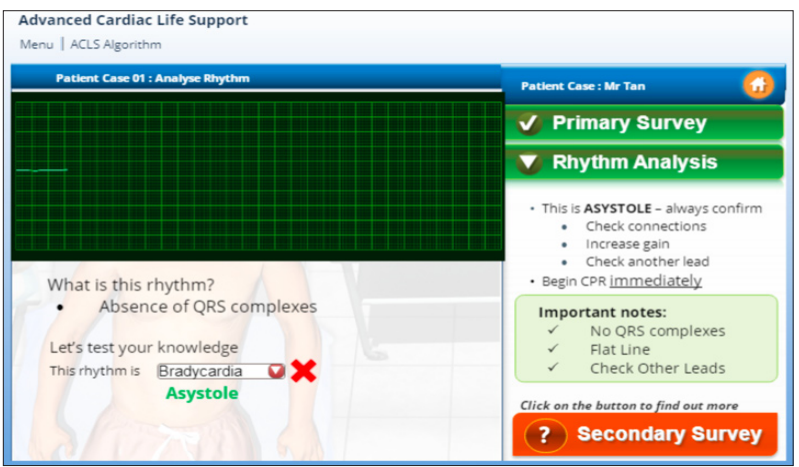

through the module. With little quizzes sprinkled through the module, it helps the participants to better recall the new and important points that are relevant and emphasized rough the various case scenarios.

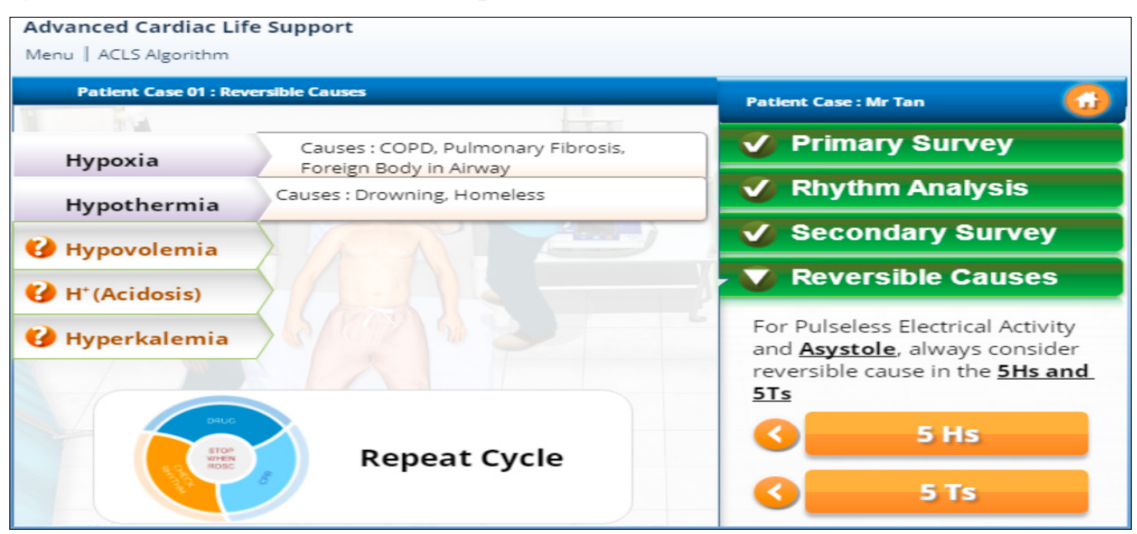

Fig7. The varying interactions

Through the scenarios, the participants would interact with the module differently to keep their minds fresh to new information. With all these new interactions that have been included in this e-learning module, nuggets of information are introduced strategically

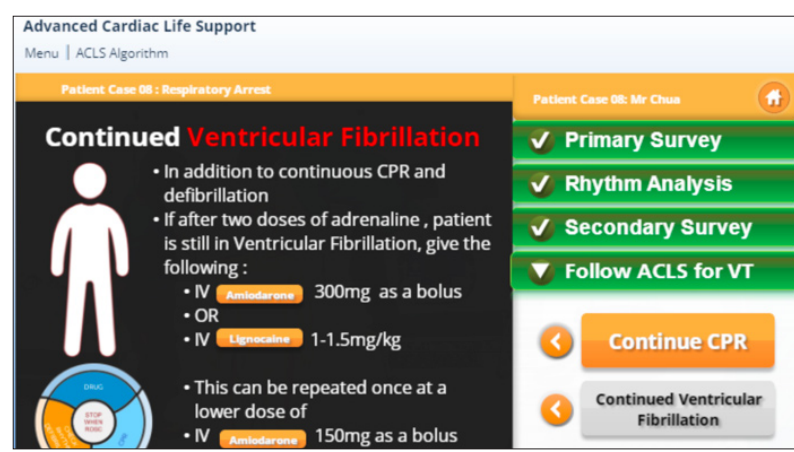

to enhance understanding and retention of the facts. This bite-sized learning, given in smaller volume as compared to the traditional face-to-face lectures where huge chunks of information are shared at once, is better received by our learners. ( Fig 7)

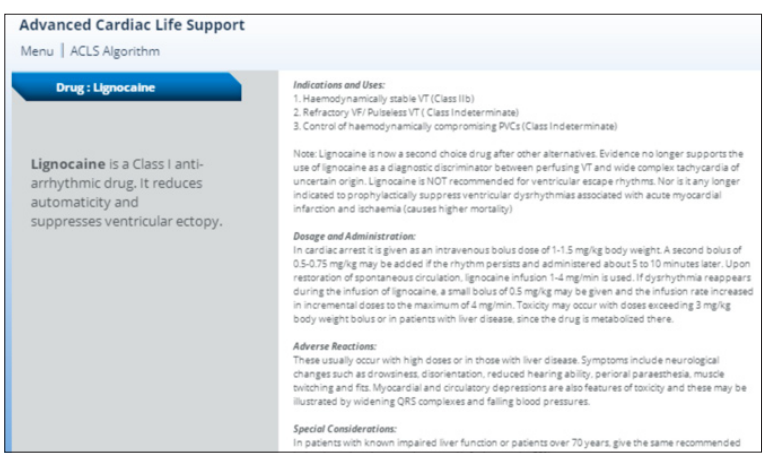

Fig8. Information at their fingertips 
Through this module, there might be medications and procedures that might need further elaboration. For example, the administration process of a certain drug, the dosage and special recommendations. The participants will have that reference and information by clicking the name of the medication and they would be led to a page detailing all they need to know about that medication. This is immensely useful and convenient for the participant as he/she would not have to flip through the whole glossary to find a single medication, it would be right where they need it. (Fig 8)

\section{Conclusion}

The hybrid ACLS modules with the added e-learning components have multiple benefits in our system. It has to be properly planned, conceptualized and executed. (Fig 9) The promotion of self-learning and empowerment, time-savings in the face to face components which is important for the busy healthcare providers, the flexibility and mobility of the learning are all positive outcomes. Some learners also feel greater psychological safety with the e-learning components as they can spend a longer time or as much time as they need to understand and assimilate the facts. This way we will see a more well-prepared learner during our face toface sessions of the ACLS course. The latter is important not just to apply the knowledge acquired, but also for the practice of handson skills, inter-professional collaborative practice and inculcating the appropriate attitude and behavior. $(7,9,21,23)$

Given the current COVID situation, with restriction on face-to-face contact time this conversion to e-ACLS could not come at a better time. Participants from different institutions from all around the campus can access the e-learning portal and access the course, be it for a refresher or as a new learner. Being able to learn at their own pace, to pause and continue as allowed by each participant's individual schedule, this would allow learners to better absorb new knowledge as well as be better equipped with most if not all the information they need for the face-to-face practical session. (24)

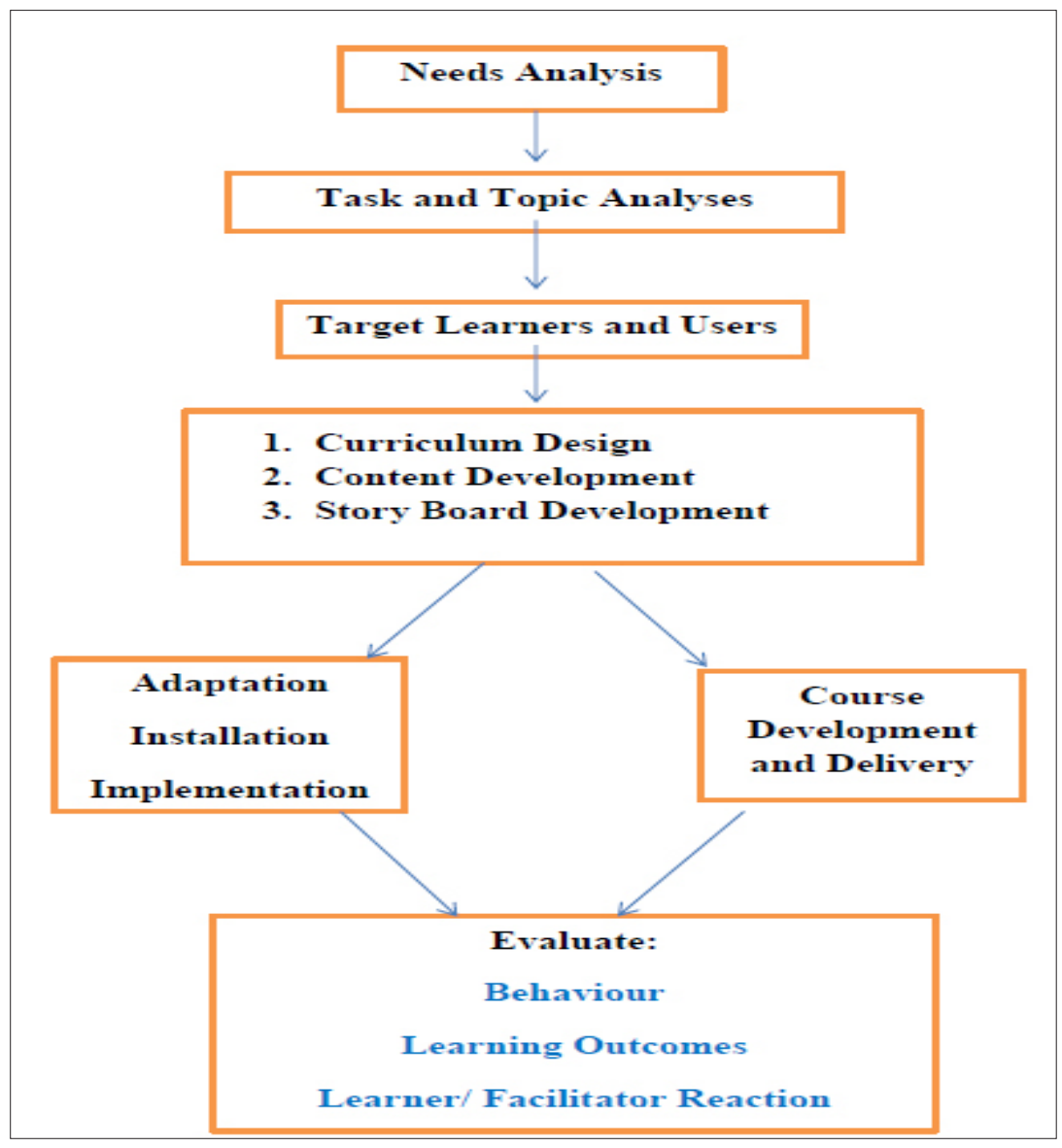

Fig9. Systematic Steps in preparing the e-learning ACLS modules 


\section{REFERENCES}

[1] Lateef F. Face to face with Coronavirus Disease 19: Maintaining motivation, psychological safety and wellness. Journal of Emergency, Trauma and Shock 2020; 13: 116-123

[2] Lateef F. Covid 19 pandemic: Disruption or a fertile experiential learning platform for emergency medicine residents. Education in Medicine Journal 2020; 12(3): 39-47

[3] Lateef F, Stawicki SP, Lee MX, Krishnan V, Sarjan A, Sirur FM et al. Infection control measures, insitu simulation and failure mode effect analysisto finetune change management during COVID 19. Journal of Emergency, Trauma and Shock 2020; 13: $239-245$

[4] Panchal AR, Berg KM, Hirsch KG, Kudenchuk PJ, Del Rios M, Cabañas JG et al. 2019 American Heart Association Focused Update on Advanced Cardiovascular Life Support: Use of Advanced Airways, Vasopressors, and Extracorporeal Cardiopulmonary Resuscitation During Cardiac Arrest An Update to the American Heart Association Guidelines for Cardiopulmonary Resuscitation and Emergency Cardiovascular Care. Circulation 2019; 140:e881-e894

[5] Magid DJ, Aziz K, Cheng A, Hazinski MF, Hoover AV, Mahgoub $\mathrm{M}$ et al. Part 2: evidence evaluation and guidelines development: 2020 American Heart Association Guidelines for Cardiopulmonary Resuscitation and Emergency Cardiovascular Care. Circulation. 2020;142(suppl 2)

[6] Sawyer KN, Camp-Rogers TR, Kotini-Shah P, Del Rios M,Gossip MR,Moitra VKetal;fortheAmerican Heart Association Emergency Cardiovascular Care Committee; Council on Cardiovascular and Stroke Nursing; Council on Genomic and Precision Medicine; Council on Quality of Care and Outcomes Research; and Stroke Council. Sudden cardiac arrest survivorship: a scientific statement from the American Heart Association. Circulation. 2020;141:e654-e685.

[7] Thorne CJ, Lockey AS, Bullock I, Hampshire S, Begum-Ali S, Perkins GD. E learning in advanced life support: An evaluation by the resuscitation council (UK) . Resuscitation 2015; 90: 79-84

[8] Perkins GD, Kimani PK, Bullock I, Clutton-Brock T, Davies RP, Gale M et al. Improving the efficiency of ACLS training: A randomized controlled trial. Ann Intern Med 2012; 157: 19-28

[9] Abdullah AA, Nor J, Baladas J, Tg Hamzah TMA, Tuan Kamauzaman TH, Md Noh AY, Rahman A. E-learning in ACLS: Outcomes and attitude among healthcare professionals. Hong Kong J Emergency medicine 2019; 27(1): 1-6

[10] Sangrà A, Vlachopoulos D, Cabrera N. Building an Inclusive Definition of E- Learning: An Approach to the Conceptual Framework. International Review of Research in Open and Distributed Learning 2012; 13 (2):145-159

[11] Lateef F. Computer-based Simulation and Online Teaching Netiquette in the Time of COVID 19. 2020; 4.8

[12] Mukhalalati BA,Taylor A. Adult Learning Theories in Context: A Quick Guide for Healthcare Professional Educators. Journal of Medical Education and Curricular Development 2019; 6: $1-10$

[13] Chacko TV. Emerging pedagogies for effective adult learning: From andragogy to heutagogy. Archives of medicine and Health Sciences 2018; 6 (2): 278-283

[14] Chua J, Lateef F. The Flipped Classroom: Viewpoints in Asian Universities. Education in Med J 2014; 6(4): e20-e26

[15] Urfa M. Flipped classroom model and practical suggestions. J Educational Tech and Online Learning 2018; 1(1): 47-59l

[16] Lateef F. Simulation-based learning: Just like the real thing. Journal of Emergency Trauma and Shock 2010; 3(4): 348-352

[17] Nestel D, Bearman M. Theory and simulationbased learning; Definition, world views and applications. Clin Simul in Nursing 2015; 11(8); 349-354

[18] Smith KK, Gilcreast D and Pierce K. Evaluation of staff's retention of ACLS and BLS skills. Resuscitation 2008; 78(1): 59-65

[19] Lateef F. Clinical reasoning: The core of medical education and practice. Int $\mathrm{J}$ of Internal and Emergency Med 2018; 1(2): 1015 
Covid 19: The Impetus to Migrate Face-To-Face ACLS to Hybrid-ACLS

[20] Schmidt HG, Mamede S. How to improve the teaching of clinical reasoning: A narrative review and proposal. Med Edu 2015; 49(10): 961-973

[21] Lateef F. Maximising Learning and Creativity: Understanding psychological safety in simulationbased learning. Journal of Emergency Trauma and Shock 2020; 13: 5-14

[22] George PP, Leong E, Ooi CK, Jarbrink K, Car J, Lockwood C. Return of investment in advanced cardiac life support training compared to face to face training in Singapore. Proceedings of Singapore healthcare 2018; 27(4): 234-242

[23] Edmondson AC, Lei Z. Psychological safety: The history, renaissance and future of inter-personal construct. Ann Rev Organ Psychiatry Organ Behav 2014; $1: 23-43$

[24] Lateef F. Inter-professional education and interprofessional practice and team science. Learning together, working together. Edu in Med J 2018; 10:81-91

Citation: Fatimah Lateef, Madhavi Suppiah, Tan Suan Kai. Covid 19: The Impetus to Migrate Face-To-Face Acls to Hybrid-ACLS. Archives of Emergency Medicine and Intensive Care. 2020; 2(2): 16-24.

Copyright: (c) 2020 Fatimah Lateef, Madhavi Suppiah, Tan Suan Kai. This is an open access article distributed under the Creative Commons Attribution License, which permits unrestricted use, distribution, and reproduction in any medium, provided the original work is properly cited. 